\title{
The Dental Values Scale: Development and Validation
}

\author{
Angela D. Langille, M.Sc.; Victor M. Catano, Ph.D.; Thomas L. Boran, D.D.S.; \\ Donald P. Cunningham, D.D.S.
}

Abstract: The purpose of this study was to produce a valid scale for use in measuring the values of dental students and practitioners - the lack of which has impeded research on professionalism in dentistry. Following standard scale development procedures, we had focus groups of dental practitioners $(\mathrm{N}=23)$ develop a ninety-nine-item pool of value terms related to dentistry. Next, Canadian dentists $(\mathrm{N}=449)$ rated the relevance of each item through an online survey. They also rated the values in a generic values measure, Schwartz's Values Scale. Exploratory and confirmatory factor analyses identified twenty-five items representing five values: Altruism, Personal Satisfaction, Conscientiousness, Quality of Life, and Professional Status. These values correlate with related dimensions from Schwartz's measure; they also correspond to the values in the American Dental Education Association's statement on professionalism. We then administered the new Dental Values Scale to dental students (N=96) to determine the relationship between practitioner and student values. First-year students were higher in Conscientiousness, Altruism, and Personal Satisfaction than practitioners, but these values decreased over time to those held by the dentists. We discuss the implication of these results and the potential value of the new scale for dental education.

Ms. Langille is employed by Sobeys National Human Resources; Dr. Catano is Professor and Chair, Department of Psychology, Saint Mary's University; Dr. Boran is Associate Professor and Dean, Faculty of Dentistry, Dalhousie University; and Dr. Cunningham, now retired, was an Associate Professor and Assistant Dean, Faculty of Dentistry, Dalhousie University. Direct correspondence to Dr. V.M. Catano, Department of Psychology, Saint Mary's University, Halifax, Nova Scotia, Canada B3H 3C3; 902-420-5845 phone; 902-496-8287 fax; vic.catano@smu.ca.

This study is based on data collected as part of Ms. Langille's master's thesis project at Saint Mary's University. A version of this article was presented at the 2009 Annual Session \& Exhibition of the American Dental Education Association.

Keywords: individual values, professionalism, ethics, measurement of dental values, dental students

Submitted for publication 2/1/10; accepted 7/20/10

$\mathrm{T}$ The yearly admissions process in dental schools is focused on determining those applicants who will most likely complete their program and become competent practitioners. Admission decisions are based on undergraduate grades, standardized tests, and interviews, among other criteria. ${ }^{1-7}$ Considering the length of a dental career, admission criteria represent a short-term focus. They do not try to predict how long future practitioners will stay in the profession, whether they will undertake a practice in an underserved rural area, whether they will work with disadvantaged groups, or if they will become interested in dental research or taking a position in a dental school. There is a lack of research that addresses these post-graduation issues. ${ }^{8}$

Masella, ${ }^{9}$ in his review of the state of professionalism in dentistry, decried the emphasis that American society, including higher education, places on a market mentality centered on expansion and profit. He identified altruism, integrity, caring, community focus, and commitment to excellence as aspects of professionalism. Writing in response to Masella's position, Botto ${ }^{10}$ argued that a balance had to be struck between fiscal responsibility and ethical and professional needs in dental education.

Many of the decisions a practitioner makes are related to the values of the new graduate, and as Masella argued, dental schools may give mixed messages to students about the importance of professionalism. Older studies on professionalism in dentistry have emphasized the importance of collecting values data from students before their admission to dental school as a means of enhancing dental student development and integration into the profession following graduation, ${ }^{11,12}$ but little research has addressed this apparent need. The research reported here addresses this perceived gap in professionalismrelated research by creating a reliable, valid tool that 
assesses values related to professionalism and the practice of dentistry.

\section{Professionalism and Values}

Professionalism plays an important role in one's success as a dentist. ${ }^{13}$ The Merriam-Webster Online Dictionary defines professionalism as "the conduct, aims, or qualities that characterize or mark a profession or a professional person." ${ }^{14}$ Masella ${ }^{9}$ cites work by Stern et al. ${ }^{15,16}$ in defining professionalism as including a set of identifiable, positive qualities or behaviors; recognizing, adopting, and upholding a code of ethics; and describing a set of values, virtues, or characteristics that serve as overarching principles for the profession. Masella claims that the most important mission of dental schools, apart from increasing knowledge and developing technical skills, is to ensure that students acquire and consistently demonstrate the "attributes of professionalism"16,17 that provide the "binding elements for creation of a unique person, the dentist" (p. 205). ${ }^{9}$

Although there is no exact definition for professionalism in health-related occupations, ${ }^{13,18}$ values are a common factor. Schwartz ${ }^{19}$ defines values as principles that guide one's behavior; in a dental context, values have been referred to as "orientations toward groups of activities seen as rewarding" (p. 1433). ${ }^{20}$ Arnold's ${ }^{18}$ review of definitions of professionalism found that several medical organizations agree that values are an important element of professionalism. For example, Epstein and Hundert ${ }^{21}$ wrote that, in addition to clinical skills and scientific knowledge, professional competence requires moral development. Definitions of professionalism include common values-related factors such as altruism, accountability, excellence, duty, self-assessment, communication, maturity, respect for others, reliability, honesty, and integrity. ${ }^{22-25}$ Recently, a task force of the American Dental Education Association (ADEA) ${ }^{26}$ developed a list of six values-based statements that it believed defined professionalism in the context of dentistry, and the ADEA House of Delegates adopted the task force's statement in 2009. The statement identifies the values of competence, fairness, integrity, responsibility, respect, and service-mindedness as the values that define professionalism in dentistry.

Some studies have tried to assess professionalism directly, mostly with respect to medical education, including one focused on moral reasoning and ethical judgment. ${ }^{27}$ According to Ranney et al., ${ }^{8}$ however, studies are lacking for evaluating criteria that may predict success in admitting students to dental school with respect to ethics and professional behavior. Masella makes the point that "assessment of the efficacy of professionalism education ... depends on valid and reliable faculty, student, and patient surveys" (p. 211). ${ }^{9}$

Some research has been done involving values related to dentistry. Arnold emphasized the importance of measuring specific values-related elements of professional behavior such as altruism, duty and service, empathy, and ethical decision making. ${ }^{18}$ Chamberlain et al. noted that measures used to assess values as part of professionalism were not necessarily related to medicine and called for future research to assess specific elements of professionalism with medicine-specific instruments. ${ }^{13}$ Similar to the medical profession, values have been measured in dentistry with instruments that were not specific to the dental profession. A dentistry-specific measure of values would likely enhance the profession's ability to evaluate those aspects of professionalism that are linked to values.

Use of generic value measures such as the Allport-Vernon-Lindzey study of values ${ }^{28}$ has produced inconsistent and often conflicting results with respect to dental values. Across studies that have used the Allport-Vernon-Lindzey scale, dental students have scored both high and low on aesthetic values, ${ }^{11,29,30}$ theoretical values, ${ }^{11,31}$ economic values, ${ }^{11,29,32}$ social values, ${ }^{30}$ and political values..$^{11,29,32}$ These inconsistent findings may result from particular sample characteristics, such as participants' geographical location or year of dental school. Nonetheless, a clear picture of dental students' values cannot be formed with data from these studies. Results from studies that used other generic value measures with dentists and dental students are no more enlightening. Becker et $\mathrm{al} .{ }^{33}$ used the Rokeach values survey (RVS) that measures eighteen terminal values (desirable conditions such as having wisdom, equality, or salvation) and eighteen instrumental values (desirable modes of conduct such as behaving in a way that is honest, capable, or loving). In that study, dentists valued family security, self-respect, happiness, freedom, inner harmony, mature love, and pleasure, but did not value a world of beauty, social recognition, world at peace, salvation, or national security. In terms of instrumental values, dentists scored high on the values of being honest, responsible, ambitious, capable, 
independent, logical, and intellectual, but scored low on the values of being polite, imaginative, obedient, forgiving, broad-minded, and clean. The RVS, however, is extremely outdated (e.g., it asks questions about Dr. Martin Luther King Jr. and Vietnam) and has mediocre reliability. Critics argue that it should not be used to make important decisions about those it evaluates. ${ }^{34}$

Loupe et al., ${ }^{12}$ using the survey of interpersonal values, found that dental students scored high on the values of support, independence, and benevolence and low on the value of leadership. Casada et al. ${ }^{35} \mathrm{de}-$ veloped a values measure specific to dental students in an educational environment. They found that dental students valued passing licensure exams, completing course requirements, and personal satisfaction. They did not provide any information on how they constructed their measure or on its reliability and validity; this lack of information makes the use of this scale questionable in any research study.

Crossley and Mubarik ${ }^{36}$ developed a measure to assess the role that values played in motivating students for a career in either medicine or dentistry. Dental students were more influenced by status and the nature of the occupation, while medical students were more motivated by values related to career opportunities, patient care, use of personal skills, and interest in science. These results suggest that medical and dental students have different sets of values; however, using a values measure common to the two professions may have excluded values information that is relevant to dentistry but not to other health care professions.

Values are an important element of professional behavior in dentistry ${ }^{26}$ and other health care professions. Past values research using generic or values measures not specific to the dental profession have produced inconsistent results. ${ }^{20}$ As well, most of the values studies cited here are dated and may not reflect values that are current in the dental profession. The lack of a reliable and valid measure of values appropriate to dentistry has impeded research on both values and professionalism in dentistry.

We sought to rectify this omission through the development of a new, valid scale designed to assess the values of dental practitioners. The study followed accepted procedures for scale development starting with identification of an item pool and ending with validation of the new scale. ${ }^{37,38}$ We next used the newly validated Dental Values Scale (DVS) to obtain normative data and to compare the values of dental students to those of dental practitioners. We expected that there might be differences between dental practitioners and the dental students since dental education is part of the process that shapes the values of students to those of the profession.

\section{Methods}

\section{Participants and Procedure}

Twenty-three dental practitioners and dental faculty members agreed to participate in one of four focus groups on dentists' values. These participants graduated from dental school between the years 1965 and 2004; on average they were 44.6 years old. There were ten male and nine female participants (four participants did not record their gender). The focus group participants were asked to discuss four values-related questions (e.g., "Write down three values that you possess and rank them in order of importance. We will discuss these values in a few minutes."). All values that were identified in at least two focus groups were retained for further review. Values mentioned in only one focus group were retained if subject matter experts (dental school faculty members) deemed them to be theoretically important. The focus group discussions together with a thorough search of the values-related literature produced a list of ninety-nine value items. Next, the participants in the focus groups, as well as members of the dental faculty $(\mathrm{N}=9)$, reviewed the final list of ninety-nine items to ensure they were meaningful and appropriate for dentistry. Feedback from the review led to the deletion of eight items.

As part of its regularly scheduled e-mail communication, the Canadian Dental Association (CDA) sent two mass e-mails to approximately 9,180 members inviting them to participate in a values-related research project. The e-mail directed individuals to the members section of the CDA website, where they found a web link to the values survey and an informed consent letter that explained the purpose of the study. They were asked to complete a survey that consisted of several demographic items, the new DVS, and Schwartz's Values Scale (SVS), a generic values scale. The survey was completely anonymous. No identifying information about who participated was recorded.

The online survey was completed by 449 dental practitioners. Data from four dentists were excluded 
because they were outliers on a substantial number of variables. In total, the final sample size for analyses consisted of 445 participants, who ranged in age from twenty-five to seventy-eight ( $\mathrm{M}=48$ years) and had graduated from dental school between the years of 1947 and 2007 (M=1985). Seventy-two percent were male. Eighty-one percent of the respondents were in general practice, 3 percent in public health, 3 percent in educational dentistry, and 13 percent in other dental specialties. Ninety-four percent practiced in urban areas, 4 percent in rural settings, and 2 percent in remote locations. Practice location options were presented to participants as follows: urban=population of at least 1,000 , rural=population under 1000 , remote $=$ rural community 80 to $400 \mathrm{~km}$ from a major regional hospital, and isolated=rural community greater than $400 \mathrm{~km}$ from a major regional hospital.

We recruited dental students from Dalhousie University, years one through four, through an email explaining the purpose of the study, requesting their participation, and inviting them to learn more about the study at a "pizza and pop party" where they could also win a gift card for books. Students received reminder e-mails about the study that included informed consent forms. Eighty-nine students out of the 160-member student population (56 percent) agreed to participate. Seven students who responded to the scale development survey and had been dropped from that analysis were added to the student sample, bringing the total sample size to ninety-six. Participants ranged in age from twentyone to forty-two $(\mathrm{M}=26.02)$ and expected to graduate from dental school between the years of 2008 and $2011(\mathrm{M}=2009)$. A little over 45 percent of the student respondents were male. Expected career type of the sample was as follows: general practice 89.4 percent, educational dentistry 1.1 percent, research 1.1 percent, and other specialty 8.4 percent. Furthermore, expected practice locations of the sample were 80 percent urban, 16.8 percent rural, and 3.2 percent remote. The distributions for career type and practice location were similar to those in the dentist sample except that a larger percentage of students expected to enter general practice (vs. 81 percent of dentists) and to practice in a rural area (vs. 3 percent of dentists). The dental students completed the same ninety-one-item scale that was used with the dentist sample. Dental students received and returned the measure as an e-mail attachment or completed the DVS as a pen-and-paper survey.
The research presented here followed ethical standards adopted by the Canadian government's federal granting agencies and was approved by the Research Ethics Boards of both Saint Mary's and Dalhousie universities.

\section{Measures}

Each of the ninety-two values in the item-pool in the DVS was embedded in a sentence that began with a phrase adapted from research carried out by Hartung et al. ${ }^{39}$ and Leong et al. ${ }^{40}$ : "In my career as a dentist, it is now or will be important that ..."followed by one of the value items such as "I have autonomy in how I carry out my work." Participants scored each item on a five-point rating scale indicating the extent of their agreement with the particular values statement $(1=$ strongly disagree to $5=$ strongly agree).

The forty-six item SVS assesses the extent that individuals judge each value statement as a guiding principle in their lives. ${ }^{19}$ Responses were measured on a five-point scale $(1=$ opposed to my values to $5=$ of supreme importance). Sample SVS items are "Protecting the environment" and "National security."

\section{Results}

\section{Factor Analysis of Value Statements}

We followed the procedures recommended by Netemeyer et al. ${ }^{38}$ and Tabachnick and Fidell ${ }^{41}$ in analyzing the survey data. First, we conducted an initial, unrotated, principle components analysis (PCA) on data randomly selected from 50 percent of the survey respondents. The initial PCA eigenvalues and scree plot indicated that the ninety-one value statements could be grouped into five factors. Next, we conducted exploratory factor analysis with principle axis factoring (PAF) with promax and varimax rotations. Because we concentrated on item reduction, the PAF was performed several times with alternating rotations, deleting items with loadings of less than .40 on each new run. The final PAF run, with promax rotation, resulted in a clear five-factor scale, with all loadings over .40 .

The final model contained sixty-one items. We labeled these underlying factors as follows: Altruism-values of being caring, considerate, and empathetic; Personal Satisfaction-values of 
harmony, self-respect, and having an enjoyable life; Conscientiousness - values of behaving ethically, competently, and dependably; Quality of Life - the values of earning a good living, achieving financial stability, and having a comfortable life; and Professional Status - the values of ambition, prestige, and belonging to a respected profession. The final model accounted for 49 percent of total variance. The first four factors had reliabilities above .90 with that for the last being .74 .

We then focused on reducing the number of items of each DVS factor. Although the sixty-one-

\section{Table 1. The Dental Values Scale}

Altruism $(\alpha=.84)$

1. I am sensitive toward others.

2. I am understanding.

3. I am kind to others.

4. I accept others despite their flaws.

5. I behave compassionately.

Personal Satisfaction $(\alpha=.88)$

6. I am satisfied with my life outside of work.

7. I have harmony in my life.

8. I am happy.

9. I am successful in my career.

10. I have quality time away from work.

Conscientiousness $(\alpha=.83)$

11. I maintain integrity (in my profession).

12. I am honest.

13. I carry out my work conscientiously.

14. I am competent.

15. I behave ethically.

Quality of Life $(\alpha=.88)$

16. I earn a good living.

17. I am well paid.

18. I maintain financial security.

19. I earn a reasonable income.

20. I achieve financial stability.

Professional Status $(\alpha=.66)$

21. I achieve prestige.

22. I am devoted to my job.

23. My work is related to the medical field.

24. I belong to a respected profession.

25. I am ambitious.

Adding Items 26 and 27 to Professional Status increases its alpha to .74 :

26. My work brings me pleasure.

27. I work with a variety of patients.

Note: Cronbach's alphas $(\alpha)$ are from the dentist sample. item DVS had a clear factor structure with excellent loadings, our priority was to maximize usability of the scale. A sixty-one-item scale could limit use of the measure in conjunction with other measures as part of the dental school selection process or with student development initiatives. Thus, we retained the top five loading items on each factor. The first four factors still maintained good reliabilities that ranged from .83 to .88 , while the reliability for the last factor was marginal at .66. Table 1 presents the final twenty-five items that resulted from this process together with the Cronbach's alpha for each scale.

\section{Confirmatory Factor Analysis and Correlations}

To assess fit of the twenty-five-item, five-factor structure of the DVS, we conducted confirmatory factor analysis (CFA) using EQS 6.1 on the entire data set obtained through the survey. We used the comparative fit index (CFI), the root mean square error of approximation (RMSEA) ${ }^{41}$ and the standardized root mean square residual (SRMR) ${ }^{42}$ to assess the fit of the model; these are fit indices most commonly recommended to assess model fit. For our data, $\mathrm{CFI}=.92$, RMSEA $=.06$, and $\mathrm{SRMR}=.05$. According to $\mathrm{Hu}$ and Bentler, ${ }^{42}$ the values of these indices for good fitting models should be CFI $\geq .95$, RMSEA $\leq .06$, and SRMR $\leq .08$. The last two indices indicated the model was a good fit, while the first suggested it was approaching a good fit. In addition to the model being a good overall fit, each item loaded significantly onto its respective scale. Individual scale items accounted for at least 22 percent of variance in the solution.

Table 2 presents the correlations between the five subscales of the DVS and the ten subscales of the SVS. We compared the DVS scales to those in the SVS that contained related values items. Thus, we looked at the correlation of Altruism in the DVS to Benevolence, Tradition, and Universalism in the SVS; Professional Status in the DVS to Power and Achievement in the SVS; and Conscientiousness in the DVS to Achievement in the SVS. Altruism was significantly and positively correlated with the SVS scales of Benevolence, Tradition, and Universalism. Professional Status was significantly and positively correlated with Power and Achievement. Conscientiousness was significantly and positively correlated with Achievement. All of these correlations range in order of magnitude from moderate to strong. The constructs of Personal Satisfaction (DVS) and 
Table 2. Correlations among DVS and SVS factors

$\begin{array}{llllllllllllll}1 & 2 & 3 & 4 & 5 & 6 & 7 & 8 & 9 & 10 & 11 & 12 & 13 & 14\end{array}$

1. Altruism

2. Personal

Satisfaction $\quad .25^{* *}$

3. Conscientiousness .45** $.30^{* *}$

4. Quality of Life $\quad .20^{* *} \quad .41^{* *} \quad .19^{* *}$

5. Professional

Status

$.31^{* *} \quad .13^{*} \quad .32^{* *} \quad .33^{* *}$

6. Universalism

$\begin{array}{lllll}.39^{* *} & .09 & .19 * * & .06 & .28^{* *}\end{array}$

7. Benevolence

$\begin{array}{llllll}.57^{* *} & .19^{* *} & .45^{* *} & .17^{* *} & .31^{* *} & .52^{* *}\end{array}$

8. Tradition

$\begin{array}{lllllll}.45^{* *} & .13^{* *} & .17^{* *} & .13^{*} & .38^{* *} & .49^{* *} & .52^{* *}\end{array}$

9. Conformity

$\begin{array}{llllllll}.34^{* *} & .08 & .24^{* *} & .11^{*} & .35^{* *} & .45^{* *} & .61^{* *} & .67^{* *}\end{array}$

10. Security

11. Power

12. Achievement

$.24 * * \quad .00$

$.24^{* *} .09$

$.14^{* *} \quad .02 \quad .04 \quad .11^{*}$

$\begin{array}{lllll}.36 * * & .50^{* *} & .49 * * & .40^{* *} & .50 * *\end{array}$

13. Hedonism

$\begin{array}{lllllllllll}.23^{* *} & .09 & .28^{* *} & .18^{* *} & .58^{* *} & .32^{* *} & .31^{* *} & .36^{* *} & .37^{* *} & .46^{* *} & .55^{* *}\end{array}$

14.

$\begin{array}{lllllllllllll}.14 * * & .14 * * & .12 * & .16^{* *} & .24^{* *} & .30^{* *} & .21^{* *} & .25^{* *} & .24^{* *} & .33^{* *} & .40^{* *} & .44^{* *}\end{array}$

14. Stimulation

$.22 * * \quad .10$

$.33^{* *} \quad .07$

$\begin{array}{llll}.21^{* *} & .14^{* *} \quad .33^{* *} \quad .40^{* *}\end{array}$

15. Self-Direction

$.37^{* *} \quad .17^{* *} \quad .39^{* *} \quad .53^{* *}$

Note: DVS factors are labeled 1 to 5 ; SVS factors are labeled 6 to 15.

${ }^{*} \mathrm{p}<.05, * * \mathrm{p}<.01$

Hedonism (SVS) appear to be similar constructs in that both depict pleasure; although we did obtain a significant, positive correlation between them, its magnitude was low. These correlations demonstrate, on the whole, that the DVS and SVS factors are addressing similar constructs and provide evidence for the construct validity of the DVS.

Data from two students were excluded from analyses: one participant was an outlier on a substantial number of variables, and the other had an irregular response pattern. The final sample size for analyses consisted of ninety-four participants. We found the same five-factor structure of the twentyfive-item scale for the dental student sample as previously noted for the dentist sample. Cronbach's alphas for the student sample were similar to those for the dentists: Altruism $\alpha=.86$, Personal Satisfaction $\alpha=.82$, Conscientiousness $\alpha=.78$, Quality of Life $\alpha=.90$, and Professional Status $\alpha=.56$.

\section{Comparing Dentist and Dental Student Values}

We conducted one-sample t-tests to assess the relationship between values of the dentists and students. We compared the responses of the students in our sample to the mean value of the dentists to control for the differences in sample sizes. We did five comparisons: first, we compared the full student sample to the dentist means, and then we examined the same relationships for the students by their year of study in dental school. Table 3 presents the results of these analyses. The only difference between all of the students and the dentists was with respect to Personal Satisfaction. Students expressed significantly more personal satisfaction with dentistry than did the dentists as a group.

Looking at the change in values across years of study in dental school shows that first-year students are significantly higher in Altruism, Personal Satisfaction, and Conscientiousness than dental practitioners. In the case of Altruism and Personal Satisfaction, the differences are largely attributable to the high degree of these values held by first- and second-year students. The results for Altruism wash out by the second year of study and reach the level of dental practitioners in subsequent years of dental school. Personal Satisfaction remains significantly higher during the second year, but then decreases to the same level as that for dentists for students in 
Table 3. Comparison of mean values on the DVS between dental students and dentists

\begin{tabular}{|c|c|c|c|c|c|c|}
\hline Factor & $\begin{array}{l}\text { Dentists } \\
N=445\end{array}$ & $\begin{array}{l}\text { All Students } \\
\qquad N=93\end{array}$ & $\begin{array}{c}\text { Fourth-Year } \\
\text { Students } \\
N=24\end{array}$ & $\begin{array}{l}\text { Third-Year } \\
\text { Students } \\
N=19\end{array}$ & $\begin{array}{l}\text { Second-Year } \\
\text { Students } \\
N=26\end{array}$ & $\begin{array}{c}\text { First-Year } \\
\text { Students } \\
N=23\end{array}$ \\
\hline $\begin{array}{l}\text { Altruism } \\
\alpha=.86\end{array}$ & $\begin{array}{l}4.39 \\
(.40)\end{array}$ & $\begin{array}{l}4.42 \\
(.43)\end{array}$ & $\begin{array}{l}4.26 \\
(.47)\end{array}$ & $\begin{array}{l}4.33 \\
(.39)\end{array}$ & $\begin{array}{l}4.50 \\
(.44)\end{array}$ & $\begin{array}{l}4.60^{*} \\
(.35)\end{array}$ \\
\hline $\begin{array}{l}\text { Personal } \\
\text { Satisfaction } \\
\alpha=.82\end{array}$ & $\begin{array}{l}4.28 \\
(.54)\end{array}$ & $\begin{array}{c}4.48^{* *} \\
(.48)\end{array}$ & $\begin{array}{l}4.36 \\
(.58)\end{array}$ & $\begin{array}{l}4.35 \\
(.43)\end{array}$ & $\begin{array}{c}4.50^{* *} \\
(.42)\end{array}$ & $\begin{array}{c}4.67^{* *} \\
(.39)\end{array}$ \\
\hline $\begin{array}{l}\text { Conscientiousness } \\
\alpha=.78\end{array}$ & $\begin{array}{l}4.65 \\
(.33)\end{array}$ & $\begin{array}{l}4.59 \\
(.36)\end{array}$ & $\begin{array}{l}4.42 * \\
(.37)\end{array}$ & $\begin{array}{l}4.49^{*} \\
(.32)\end{array}$ & $\begin{array}{l}4.60 \\
(.38)\end{array}$ & $\begin{array}{c}4.85^{* *} \\
(.16)\end{array}$ \\
\hline $\begin{array}{l}\text { Quality of Life } \\
\alpha=.90\end{array}$ & $\begin{array}{l}4.17 \\
(.58)\end{array}$ & $\begin{array}{l}4.07 \\
(.61)\end{array}$ & $\begin{array}{l}4.02 \\
(.61)\end{array}$ & $\begin{array}{l}3.95 \\
(.72)\end{array}$ & $\begin{array}{l}4.08 \\
(.50)\end{array}$ & $\begin{array}{l}4.25 \\
(.63)\end{array}$ \\
\hline $\begin{array}{l}\text { Professional Status } \\
\alpha=.56 \text { for five items }\end{array}$ & $\begin{array}{l}4.10 \\
(.50)\end{array}$ & $\begin{array}{l}4.11 \\
(.46)\end{array}$ & $\begin{array}{l}4.15 \\
(.39)\end{array}$ & $\begin{array}{l}4.11 \\
(.42)\end{array}$ & $\begin{array}{l}4.02 \\
(.58)\end{array}$ & $\begin{array}{l}4.16 \\
(.43)\end{array}$ \\
\hline
\end{tabular}

shown in Table 1

Notes: Standard deviations (SD) are in parentheses. Cronbach's alphas $(\alpha)$ are from the student sample. One-sample t-test with 2-tailed level of significance. All comparisons are between the indicated student sample mean and the mean of the dentists across the five value scales.

${ }^{*} \mathrm{p}<.05,{ }^{* *} \mathrm{p}<.001$

their third and fourth years of study. Conscientiousness is different in that there is a steady decrease in its level from first- to fourth-year students. In the case of third- and fourth-year students, the level of Conscientiousness actually is significantly lower than that of practitioners. There were no significant differences between the dentists and students, at any year of study, for the values of Quality of Life or Professional Status.

\section{Discussion}

The primary purpose of our study was to develop and validate a psychometrically sound measure of dental values. Although dentists' and dental students' values have been measured in the past, they have been done with generic measurement scales that have not identified a clear picture of values related to dentistry. Our final results based on work with both dentists and dental students produced a twenty-fiveitem, five-factor model, which we named the Dental Values Scale. The five factors are Altruism, Personal Satisfaction, Conscientiousness, Quality of Life, and Professional Status. Internal consistencies of four of the DVS factors were very good (.83 to .88); internal consistency of Professional Status (.66) was marginal. These internal consistency values suggest that on the whole the DVS is a reliable measurement tool. The DVS and Schwartz's Values Scale contain common elements: helping, caring for, and respecting others; prestige and public perception; and competence. Correlations between factors of the DVS and SVS showed positive relationships between the common elements, thereby providing validity evidence for the DVS. These results indicated that the DVS is a valid measure of dental values.

We also validated the DVS with a sample of dental students. We found the same factor structure and levels of internal consistency for both samples. We also found that dentists and dental students had similar mean levels on the values of Altruism and Professional Status, Quality of Life, and Personal Satisfaction, but differed with respect to Conscientiousness. Analyzing the data by the student's year of study brought to the fore some interesting results. In their first year of study, students are significantly higher in terms of Altruism, Personal Satisfaction, and Conscientiousness. This may represent an "elation" effect at being admitted to dental school and recognizing the need to work hard to maintain that status. Both Altruism and Personal Satisfaction decrease among third- and fourth-year students until those values reach the same level expressed by practitioners. Conscientiousness, on the other hand, decreased across all four years until it was significantly lower in the 
fourth year than that expressed by dentists. This may represent in part a "relaxation" effect in that senior students know the realistic amount of work needed to complete the program. What may be needed is some reinforcement to prevent conscientiousness from slipping further and to give the fourth-year students a more realistic expectation of the level of conscientiousness needed for success in dental practice. The changes across years of dental study are cross-sectional and may represent differences in students admitted in each of those years; these results should be taken as suggestive pending examination of longitudinal study of changes within the same cohort of students. These results do suggest that the DVS is tapping into values relevant not only to dentists but to dental students. For the most part, it suggests that the DVS can be used with both populations.

A word of caution must be made with respect to the Professional Status value scale. Both in the case of the dentists and the dental students, the internal consistency was marginal, reaching .66 and .56 respectively. These data suggested that this value scale needed further work by improving the scale items or adding new ones to bring its reliability up to the level found in the other widely used scales. Only seven items had loaded onto the Professional Status scale in our original factor analysis, with two items having factor loadings below our criterion of .40 for inclusion in the scale. The loadings for these two deleted items were still above .30, which is an acceptable factor loading. When we include these two items in the Professional Status scale, its reliability increases to .74 for the dentist sample and .66 for the student sample. These values are not as high as we would have liked, but they make use of the Professional Status scale more acceptable. We have included these two additional items as items 26 and 27 in Table 1.

By way of comparison, the reliabilities of some of the most widely used personality measures fall within the same range as the DVS. For example, scales from the NEO-PI-R have coefficient alphas that range from .67 to .85 ; those for the 16 Personality Factors (16PF) range from .68 to .80 ; scales for the International Personality Item Pool (IPIP) range from .73 to .86; and those for the California Psychological Inventory (CPI) range from .53 to $.88 .^{43}$ Goldberg states that a goal in developing the popular IPIP was to have ten-item scales in which reliabilities ranged from .70 to .90 with an average of $.80 .{ }^{43}$ The reliabilities of the DVS fall into this range. We thus believe the DVS is suitable for both research and counseling purposes.

\section{Other Values Studies}

At the outset we noted the dearth of research on values in dentistry and attributed this lack of knowledge to the absence of a measure that was designed specifically for that profession. Our research takes an important initial step in filling this gap by establishing a reliable and valid measure that assesses values specifically related to the dental profession. Our research found that there are five broad factors that can be used to describe dentists' values: Altruism, Personal Satisfaction, Conscientiousness, Quality of Life, and Professional Status. The measurement tool created in the current research reliably and validly assesses these five broad factors for both dentists and dental students.

Concurrent with this study, ADEA released its statement on professionalism in dental education. ${ }^{26}$ The ADEA Task Force on Professionalism in Dental Education developed its set of values through a rational process, compared to the empirical approach used here. Table 4 compares the ADEA values statement with the values assessed by the DVS. We argue that the six ADEA values overlap with three of the DVS values. Altruism includes the ADEA values of Service-Mindedness and Respect; Conscientiousness includes the ADEA values of Competence, Integrity, and Fairness; and Professional Status overlaps with the ADEA value of Responsibility. There are no ADEA values that align with Personal Satisfaction and Quality of Life. Botto ${ }^{10}$ argued that a balance needs to be struck between fiscal responsibility and ethical and professional needs in dental education. We agree with that assessment and add that Quality of Life must also be included as part of dental education. Our data offer evidence that both dental students and practitioners value both Professional Status and Quality of Life as part of professionalism. Financial security and quality of life cannot be ignored; however, the key here is balance. Dental students should not be so consumed by market forces and financial security that they lose sight of altruism and other professional values. The DVS provides a mechanism for evaluating the relative importance of these factors in both the life of dental students and practitioners. 
Table 4. Comparison of DVS and ADEA values statements

\section{Service-Mindedness}

Acting for the benefit of the patients and the public we serve and approaching those served with compassion.

\section{Altruism}

Being caring, considerate, and empathetic. Behaving compassionately and showing kindness and understanding to others.

\section{Respect}

Honoring the worth of others.

\section{Competence}

Acquiring and maintaining the high level of special knowledge, technical ability, and professional behavior necessary for the provision of clinical care to patients and for effective functioning in the dental education environment.

\section{Integrity}

Being honest and demonstrating congruence among one's values, words, and actions.

\section{Fairness}

Demonstrating consistency and even-handedness in dealings with others.

\section{Conscientiousness}

Behaving ethically, competently, and dependably. Being honest and acting with integrity.

\section{Responsibility}

Being accountable for one's actions and recognizing and acting upon the special obligations to others that one assumes in joining a profession.

\section{Professional Status}

Ambition, prestige, and belonging to a respected profession.

\section{Personal Satisfaction}

Having harmony, self-respect, and an enjoyable life. Being satisfied with life outside work and having a successful career.

\section{Quality of Life}

Earning a good living, achieving financial stability and security, and having a comfortable life.

Source for ADEA values statements: American Dental Education Association (ADEA). ADEA statement on professionalism in dental education. J Dent Educ 2009;73(7):860-5.

\section{Practical Applications}

The DVS could be a valuable values training tool in dental school curricula. If the DVS suggested that students did not exhibit values essential for professionalism in dentistry, then a developmental program could be put in place. For example, faculty members deemed to be exemplars of dental values could serve as mentors and models for students with respect to successful dental values. Furthermore, dental schools could make changes to their curricula to include courses on values-related material and could create systems that acknowledge and reward students who demonstrate appropriate values. One dental school has already begun the process of en- hancing values in its curriculum by initiating a course on mindfulness, which concentrates on issues such as self-awareness and quality of life. ${ }^{44}$ The use of the DVS could be used to assess the efficacy of mindfulness training with respect to increasing professionalism and the students' quality of life.

The DVS also has the potential to serve as a diagnostic tool with dental practitioners. Every year a substantial number of dentists leave the profession. Perhaps a counseling program initiated by dental schools or dental societies could provide dentists with an understanding of their values compared to normative data for the profession. Strategies could be put in place to reconcile the differences in values, 
if possible, or to help the dentist transition to a new career or profession that is more in keeping with his or her personal values.

Ranney et al. ${ }^{8}$ noted the lack of any assessment of values relevant to dentistry as part of the admission criteria for dental schools in both the United States and Canada. They recommended that dental schools address important societal needs in addition to preparing students for dental practice and research and that dental schools consider societal needs as part of their individual missions, goals, and objectives. The DVS may provide a means of assessing whether admissions criteria lead to a balanced student body that values community practice, practice in rural areas, research, and obtaining faculty positions in dental school, along with entering into successful private practice.

Towards that goal, the DVS might also be used as part of the battery of selection tools used to admit students to dental schools. There is a considerable waste of time and money if students proceed through school but never take up dental practice. The DVS might indicate that students selected for the dental program are predisposed to become principled, professional dentists. Using the DVS as part of admissions could identify those students who are outliers with respect to dental values. This is not to argue that there should be homogeneity among students admitted to dental school. Using the DVS as only one measure among several would still provide for diversity among the entering cohort.

\section{Limitations}

Two limitations arise from our study design. First, our dental student sample came from a single dental school. These students' values may not be the same as those reported by students at other schools, although they were similar to a national sample of dental practitioners. Nonetheless, additional research should be conducted with students from other schools to determine if they share the same values as students in this study. Our sample is also comprised of Canadian students, although for the most part we would expect that they share similar values with their counterparts in the United States. We were not able to obtain any criterion-related validity evidence for the DVS. Future research should obtain performance data to determine the extent to which the DVS predicts important outcomes such as job performance, client satisfaction, or success in dental school.
The second limitation concerns the relatively low response rate of 4.9 percent. We received responses from 449 dentists when we invited the CDA membership of 9,180 to participate. In studies based on a random, targeted sample, a response rate of 30 percent is considered acceptable although lower rates do occur. In our situation, the sample is more like a poll in which the accuracy and generalizability of the data rely more on the size of the sample than the response rate. We estimate that the data presented for our sample are accurate to within a sampling error of \pm 5 percent. The best verification of the results presented here is validation through replication; however, the consistency of the values we identified with those reported by Masella ${ }^{9}$ and ADEA help to establish their accuracy in representing the values of dental professionals. Similarly, the correlations with values from Schwartz's scale presented in Table 2 further strengthen the generalizability of these data. Schwartz's theory and scale have been verified in over 200 studies in sixty countries. ${ }^{45}$

\section{Conclusions and Future Research}

Dental schools often have difficulty in recruiting dentists to join their faculty or to undertake dental research. Only 2 percent of our student sample expressed an interest in a career in either education or research. The number of students expecting to undertake careers in the venues outside of general practice was not large enough for us to make meaningful comparisons with respect to their values compared to those opting for more traditional careers. Developing value profiles for dental students with respect to their interests in education and research could help admissions committees identify those students with an interest in pursuing these types of dental careers. Much more data need to be collected to establish valid profiles for these different paths.

Similarly, future research should establish whether there are differences among values of dentists who work in dental specialty areas. Are the values of dentists in academia different from values of dentists in general practice? Are the values of dentists in general practice different from those in public health or other specialties? The distribution of dentists in these areas was not large enough for us to conduct meaningful comparisons. Obtaining such 
information would equip mentors and dental faculty members to advise students who are undecided about the areas of dentistry they might find suitable. For example, students exhibiting high levels of the value Personal Satisfaction might be more suited to pursue a career in academia if dentists in academia also tend to demonstrate high levels of Personal Satisfaction.

The comparisons between dental students and dental practitioners deserve some comment. While our results are cross-sectional, they do suggest that for Altruism, Personal Satisfaction, and Conscientiousness there is a decrease in these values from high starting points to values close to those expressed by practitioners. Future longitudinal research needs to determine whether these changes are the result of the dental school environment or culture in shaping students to the values held by dentists. These results do show that the DVS can be used to assess changes in dental students' values throughout their progress in dental school and can be used to monitor student values as they become practitioners.

\section{Acknowledgments}

We thank the Canadian Dental Association and its staff for their most helpful cooperation, as well as the dentists and dental students who participated in our study. Without their cooperation, this study would not have been possible.

\section{REFERENCES}

1. Dworkin SF. Dental aptitude tests as predictors of performance over four years of dental school: analysis and interpretation. J Dent Educ 1979;34:58-62.

2. Kramer GA. Predictive validity of the dental admission test. J Dent Educ 1986;50(9):526-31.

3. Oudshoorn WC. The utility of Canadian DAT perceptual ability and carving dexterity scores as predictors of psychomotor performance in first-year operative dentistry. J Dent Educ 2003;67(11):1201-8.

4. Poole A, Catano VM, Cunningham DP. Predicting performance in Canadian dental schools: the new CDA structured interview, a new personality assessment, and the DAT. J Dent Educ 2007;71(5):664-76.

5. Sandow PL, Jones AC, Peek CW, Courts FJ, Watson RE. Correlation of admission criteria with dental school performance and attrition. J Dent Educ 2002;66(3):385-92.

6. Smithers S, Catano VM, Cunningham DP. What predicts performance in Canadian dental schools? J Dent Educ 2004;68(6):598-613.

7. Thompson GW, Ahlawat K, Buie R. Evaluation of the dental aptitude tests components as predictors of dental school performance. J Can Dent Assoc 1979;45:407-9.

8. Ranney RR, Wilson MB, Bennett RB. Evaluation of applicants to predoctoral dental education programs: review of the literature. J Dent Educ 2005;69(10):1095-106.
9. Masella RS. Renewing professionalism in dental education: overcoming the market environment. J Dent Educ 2007;71(2):205-16.

10. Botto RW. Addressing the marketplace mentality and improving professionalism in dental education: response to Richard Masella's "Renewing professionalism in dental education.” J Dent Educ 2007;71(2):217-21.

11. Cain MJ, Silberman SL, Mahan JM, Meydrech EF. Changes in dental students' personal needs and values. J Dent Educ 1983;47(9):604-8.

12. Loupe MJ, Meskin LH, Mast TA. Changes in the values of dental students and dentists over a ten-year period. J Dent Educ 1979;43(3):170-5.

13. Chamberlain TC, Catano VM, Cunningham DP. Personality as a predictor of professional behavior in dental school: comparisons with dental practitioners. J Dent Educ 2005;69(11):1222-37.

14. Merriam-Webster's online dictionary. At: www.m-w.com/ dictionary/professionalism. Accessed: April 15, 2007.

15. Stern DT, ed. Measuring medical professionalism. New York: Oxford University Press, 2006.

16. Stern DT, Frohna AZ, Gruppen LD. The prediction of professional behavior. Med Educ 2005;39(1):75-82.

17. Schour I. Objectives of dental education. J Dent Educ 1960; 24(4):256-60.

18. Arnold L. Assessing professional behavior: yesterday, today, and tomorrow. Acad Med 2002;77(6):502-15.

19. Schwartz S. Are there universal aspects in the structure and contents of human values? J Soc Issues 1994;50(4):19-45.

20. Chambers, D. The role of dentists in dentistry. J Dent Educ 2001;65(12):1430-40.

21. Epstein R, Hundert E. Defining and assessing professional competence. JAMA 2002;287(2):226-34.

22. Project professionalism. Philadelphia: American Board of Internal Medicine, 1994.

23. Gibson DD, Coldwell LL, Kiewit SF. Creating a culture of professionalism: an integrated approach. Acad Med 2000;75(5):509-10.

24. Miller GD, Frank D, Franks RD, Getto CJ. Noncognitive criteria for assessing students in North American medical schools. Acad Med 1989;64(1):42-5.

25. Phelan S, Obenshain S, Galey WR. Evaluation of the noncognitive professional traits of medical students. Acad Med 1993;68(10):799-803.

26. American Dental Education Association (ADEA). ADEA statement on professionalism in dental education. J Dent Educ 2009;73(7):860-5.

27. Bebeau MJ, Thoma SJ. The impact of a dental ethics curriculum on moral reasoning. J Dent Educ 1994;58(9): 684-92.

28. Allport G, Vernon P, Lindzey G. Manual: study of values. Boston: Houghton Mifflin, 1970.

29. Silberman SL. Comparison of personal values among freshman and senior dental students and dental faculty. J Dent Educ 1976;40(6):334-9.

30. Silberman SL. Standardization of value profiles of dental students and dental faculty. J Dent Res 1976;55(6): 939-50.

31. Manhold J, Shatin L, Manhold B. Comparison of interest, needs, and selected personality factors of dental and medical students. J Am Dent Assoc 1963;52:1601-5. 
32. McDaniel SP, Siler WM, Isenberg BP. Comparison of personality variables and values among dental students, practitioners, and faculty. J Dent Educ 1988;52(3):156-9.

33. Becker BW, Kaldenberg DO, Connor PE. Dentists' personal values: an exploratory investigation. J Am Dent Assoc 1996;127(4):503-9.

34. Brookhart S, Sanford E, eds. The twelfth mental measurements yearbook. Lincoln, NE: Buros Institute of Mental Measurements, 1995.

35. Casada JP, Willis DO, Butters JM. An investigation of dental student values. J Am Coll Dent 1998;65:36-41.

36. Crossley ML, Mubarik A. A comparative investigation of dental and medical students' motivation towards career choice. Br Dent J 2002;193(8):471-3.

37. DeVellis RF. Scale development: theory and applications, 2nd ed. Thousand Oaks, CA: Sage, 2003.

38. Netemeyer RG, Bearden WO, Sharma S. Scaling procedures: issues and applications. Thousand Oaks, CA: Sage, 2003.

39. Hartung PJ, Taber BJ, Richard GV. The physician values in practice scale: construction and initial validation. J Voc Behav 2005;67(2):309-20.
40. Leong F, Hardin E, Gaylor M. Career specialty choice: a combined research-intervention project. J Voc Behav 2005;67(1):69-86.

41. Tabachnick B, Fidell L. Using multivariate statistics, 5th ed. Toronto: Allyn and Bacon, 2007.

42. Hu L, Bentler P. Cutoff criteria for fit indexes in covariance structure analyses: conventional criteria versus new alternatives. Struct Eq Mod 1999;6(1):1-55.

43. Goldberg LR. A broad-bandwidth, public domain, personality inventory measuring lower-level facets of several five-factor models. In: Mervielde I, Deary I, De Fruyt F, Ostendorf F, eds. Personality psychology in Europe, vol. 7. Tilburg, The Netherlands: Tilburg University Press, 1999:7-28.

44. Lovas JG, Lovas DA, Lovas PM. Mindfulness and professionalism in dentistry. J Dent Educ 2008;72(9):998-1009.

45. Roccas S, Sagiv L, Schwartz SH, Knafo A. The big five personality factors and personal values. Pers Soc Psychol Bull 2002;28(6):789-801. 